\title{
Psychosocial aspects of epilepsy in Nigeria: a review
}

\section{A Akinsulore1, A Adewuya²}

1Department of Mental Health, Obafemi Awolowo University Teaching Hospitals Complex, Wesley Guild Hospital, Ilesa, Osun State, Nigeria 2Department of Behavioural Medicine, Lagos State University College of Medicine, Ikeja, Lagos, Nigeria

\begin{abstract}
Background: Epilepsy is a chronic disorder marked by intermittent, often unpredictable seizures which may be embarrassing and disruptive to the normal activity of daily living. This review was undertaken to provide information / data on the prevalence, seizure types, treatment issues and psychosocial impact of epilepsy in Nigeria. Method: We searched the PUBMED database with emphasis on studies conducted in Nigeria using a combination of the following words: epilepsy, seizure, convulsion, prevalence, epidemiology, psychiatric morbidity, social issues, quality of life, cognition, school performance, treatment issues and Nigeria. Result: 48 relevant studies that met the criteria were reviewed. The point prevalence of epilepsy varies from 5.3 to 37 per 1000 in Nigeria. Most studies showed a predominance of generalized tonic-clonic seizures. Nigerian patients with epilepsy suffer social deprivation and discrimination in education, employment, housing, marital life as well as associated psychiatric morbidity. Conclusion: Epilepsy, a stigmatizing disorder in Nigeria, has a significant impact on the day to day functioning of those with the condition.
\end{abstract}

Keywords: Epilepsy; Psychosocial; Nigeria

Received: 23-04-2009

Accepted: 04-12-2009

\section{Introduction}

Epilepsy is a chronic disorder marked by intermittent, often unpredictable seizures with associated significant psychological and social consequences for everyday living. ${ }^{1}$ People with the condition report a significant impact of the disease and its management in terms of family dysfunction, reduced social and leisure opportunities and increased levels of psychiatric comorbidity and poor self esteem compared with people without the condition. ${ }^{2}$

It is important to recognize the complex psychosocial implications inherent in the diagnosis of epilepsy. Furthermore the stigmatizing nature and unpredictability of the nature and course of epilepsy is a key factor in the psychosocial handicaps it engenders ${ }^{3}$ Beliefs triggered by the unpredictability of the condition appear to render

\section{Correspondence}

Dr. A Akinsulore

Department of Mental Health, Obafemi Awolowo University

Teaching Hospitals Complex, Wesley Guild Hospital, Ilesa

Osun State. Nigeria

email: sanmilore@yahoo.com individuals susceptible to psychopathology. ${ }^{3}$ Cognitive impairment associated with epilepsy may have deleterious effects on education, vocation, social and family life of affected individuals. ${ }^{4,5}$

This review was undertaken to provide information / data on the prevalence, seizure types, treatment issues and psychosocial impact of epilepsy in Nigeria

\section{Method}

The Pubmed database (1966-2009) was searched for studies conducted in Nigeria using a combination of the following search words: epilepsy, seizure, convulsion, prevalence, epidemiology, psychiatric morbidity, social issues, quality of life, cognition, school performance, treatment issues and Nigeria. Articles were included if they had at least an abstract in English published in peerreviewed journals and were conducted in Nigeria

\section{Data collection and analysis}

A total of 242 articles were found using PUBMED. Articles were assessed by both authors for methods and results detailing prevalence, psychiatric morbidity, quality of life, social issues, treatment issues, cognition and school 
performance. The selection process yielded 48 articles suitable for inclusion (Figure 1).

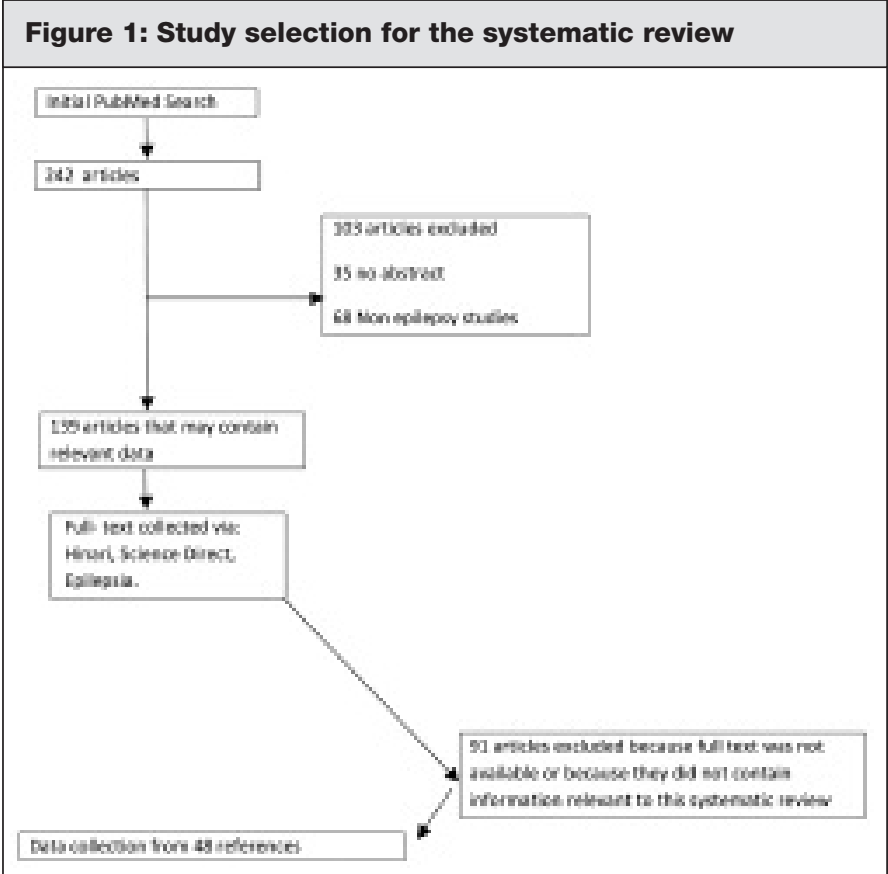

\section{Results}

Prevalence of epilepsy in Nigeria

Epilepsy is the most common non-infectious neurological disease in developing countries, including Nigeria. ${ }^{6,7}$ It is estimated that the condition affects approximately 50 million people worldwide, around 40 million of them living in developing countries. ${ }^{8}$ From the small number of communitybased studies available the point prevalence of epilepsy varies from 5.3 to 37 per 1000 in Nigeria. 9-1 l (Table I)
Dada $^{12}$ in Lagos estimated the prevalence of epilepsy as 13 per 1000 based on a survey of attitudes towards epilepsy among members of 381 households. A pilot study conducted in Aiyete, a rural community in Nigeria with a population of 1200, estimated a prevalence of 37 per 1000. ${ }^{10}$ In another rural community study from Udo, using a door-to-door survey, the point prevalence of epilepsy per 1000 was 6.2.13 In a further community survey from Igbo-Ora ${ }^{11}$, the crude prevalence (per 1000) of active epilepsy was 5.1 for males, 5.6 for females and 5.3 for the total population. The variations may be largely due to differences in methodological approaches (community, door-to-door, active case seeking out of patients versus hospital based or other passive ascertainment), definition of epilepsy, investigation and other local factors such as impact of social factors and beliefs and factors specific to different geographic zones e.g. infection. ${ }^{14}$ Although some earlier studies have tried to estimate the prevalence of epilepsy in Nigerial5-17, they were conducted in clinical settings and were beset with methodological problems and so not included in this review.

The proportion of different types of epilepsy may still be unknown in Nigeria. While some studies (Table II) showed a predominance of generalised tonic clonic seizures ${ }^{9,12,19-23}$, other studies found a higher representation of partial seizures. ${ }^{11,18,24}$ Possible explanation for the disparities in the predominant seizure types could be due to the differences in the settings where the studies were conducted (clinical/community based) and the lack of standardized classification and terminology in epilepsy research in Nigeria. Further the lack of specialized physicians and diagnostic equipment could lead to misclassification of seizure type. Therefore, community-based studies with electroencephalographic recording are required to enable accurate clinical classification of epilepsy in Nigeria.

\section{Table I: Prevalence of epilepsy in Nigeria}

\begin{tabular}{|l|l|l|l|l|}
\hline Reference & Author & Year & N & Prevalence/1000 \\
\hline 12 & Dada & 1970 & 381 (household) & 13.0 \\
10 & Osuntokun et al. & 1982 & 903 & 37.0 \\
11 & Osuntokun et al. & 1987 & 18,954 & 5.3 \\
13 & Longe \& Osuntokun & 1989 & 2925 & 6.2 \\
\hline
\end{tabular}

\section{Table II: Proportion of seizure types in patients with epilepsy in Nigeria (proportions are percentages)}

\begin{tabular}{|c|c|c|c|c|c|c|c|c|c|c|}
\hline Reference & Author & Year & N & GTCS & Abs & SPS & CPS & $P S G$ & Other & NC \\
\hline & $\begin{array}{l}\text { Dada } \\
\text { Danesi } \\
\text { Osuntokun et al. } \\
\text { lloeje } \\
\text { Ahmed \& Obembe } \\
\text { Ojuawo \& joiner } \\
\text { Ogunniyi \& Oluwole } \\
\text { Ogunlesi et al. }\end{array}$ & $\begin{array}{l}1970 \\
1985 \\
1987 \\
1989 \\
1991 \\
1997 \\
1998 \\
2009\end{array}$ & $\begin{array}{l}117 \\
945 \\
101 \\
580 \\
351 \\
98 \\
345 \\
126\end{array}$ & $\begin{array}{l}51.2 \\
17.9 \\
23 \\
57.0 \\
33.5 \\
62.0 \\
38.0 \\
76.9\end{array}$ & $\begin{array}{l}0.8 \\
1.2 \\
3 \\
2.0 \\
3.9 \\
6.0 \\
- \\
2.4\end{array}$ & $\begin{array}{l}19.7 \\
25.0 \\
4 \\
4.0 \\
13.3 \\
1.0 \\
8.0 \\
-\end{array}$ & \begin{tabular}{|l|}
9.4 \\
34.0 \\
52 \\
12.0 \\
14.1 \\
17.0 \\
28.0 \\
6.3
\end{tabular} & \begin{tabular}{|l|}
8.5 \\
17.2 \\
- \\
- \\
22.7 \\
- \\
18.0 \\
1.6
\end{tabular} & $\begin{array}{l}- \\
1.7 \\
- \\
- \\
6.0 \\
14 \\
- \\
-\end{array}$ & $\begin{array}{l}10.4 \\
3.0 \\
18 \\
25 \\
6.5 \\
- \\
8.0 \\
-\end{array}$ \\
\hline
\end{tabular}

$\mathrm{N}=$ number of patients with epilepsy; GTCS= generalized tonic-clonic seizure; Abs= absences; SPS= simple partial seizure; CPS= complex partial seizure; $\mathrm{PSG}=$ partial seizure secondarily generalised; $\mathrm{NC}=$ not classified. studies in children. 


\section{Psychiatric morbidity in epilepsy}

Behavioural symptoms in patients with epilepsy may occur in the prodrome to a seizure (which may precede actual seizure by minutes to hours and does not occur in every patient); during the ictus; as part of the post ictal phase; and interictally. Evidence from a significant number of studies in Nigeria confirms that epilepsy is associated with an increased level of psychiatric morbidity. ${ }^{25-28}$ However methodological differences limit comparability of the results of most studies. Also the identification of psychiatric morbidity among epileptics was commonly conducted without the use of standardized instruments and psychiatric diagnoses were made without reference to any standard criteria.

In adults, using the Clinical Interview Schedule (CIS), Gureje ${ }^{25}$ found a prevalence of $37.3 \%$ of psychiatric morbidity amongst an unselected sample of 204 patients with epilepsy attending a neurological out-patient clinic in Southwestern Nigeria. The study found that patients with partial seizure of temporal lobe origin were the most psychiatrically impaired, while those with partial seizure of non-temporal lobe origin the least. The commonest psychiatric diagnoses included schizophrenia-like psychoses followed by depressive disorder, anxiety disorder and personality disorder. Personality disorders or the symptom constellation referred to as epileptic personality was common among patients with primary generalized epilepsy

Research in Nigeria has documented that people with epilepsy are more likely to experience anxiety, depression and low self esteem. ${ }^{26-28}$ Fatoye et $\mathrm{al}^{27}$ in a controlled study of 52 epileptic patients used the Hospital Anxiety and Depression scale (HADS) and found a statistically significant difference in anxiety and depression symptoms between patients with epilepsy and healthy controls. Anxiety symptoms were significantly associated with polypharmacotherapy (possibly reflecting poor seizure control) while depression symptoms were significantly associated with longer duration of epilepsy. Also, Okubadejo28 evaluated 212 adults with epilepsy using the Zung's selfrating depression scale (SDS) and found a rate of $26 \%$ with clinically significant depressive symptoms. Olley ${ }^{29}$ had earlier examined the effect of psychosocial and seizure factors on Depression and Neurotic Disorders among clinically diagnosed Nigerian patients, with epilepsy. Significant main effect for seizure control, stigma, emotional adjustment, vocational adjustment, interpersonal adjustment, adjustment to seizures were recorded on depression while significant main effect for seizure control, stigma, emotional adjustment, adjustment to seizures were recorded for neurotic disorders.

In children, Iloeje ${ }^{19}$ had earlier reported that $18 \%$ of the 580 epileptic patients attending an outpatient clinic in Eastern Nigeria (1985 to 1987) were mentally retarded. Episodes of status epilepticus, early age of onset of seizure and long delay before presentation to the hospital were found to be associated with mental retardation in these children. In another study in central Nigeria, 98 children with epilepsy were followed up over a period of 2 years and hemiplegia, hyperactivity, irrational behaviour, expressive aphasia, mental subnormality, deafness and blindness were observed commonly in these children. ${ }^{21}$

A more recent study using the Diagnostic Interview Schedule for children version IV (DISC- IV) examined anxiety and depressive disorders in 102 adolescents with epilepsy in southwestern Nigeria. ${ }^{26}$ While the reported prevalence of anxiety disorders was $31.7 \%$, that of depressive disorders was $28.43 \%$. In this study, uncontrolled seizures, poly-pharmacotherapy and felt stigma were associated with anxiety or depressive disorders. In a larger study of 166 adolescents with epilepsy and their adult carers interviewed using the DISC-IV, the prevalence of any psychiatric disorder was 65.1\%; any anxiety disorder was 33.1\%; any depressive disorder was 30.1, and any disruptive behavior disorder was 25.9\%.30 These proportions were higher than those in healthy controls and psychiatric morbidity was mainly associated with frequency of seizures in this study.

\section{Quality of life in epilepsy}

Epilepsy has been observed to significantly impact on the quality of life (QOL) of the sufferers. ${ }^{31}$ This concept of QOL in epilepsy encompasses physical health (general health and daily function, seizure frequency and severity and medication side effects), mental health (emotional wellbeing and self esteem) and social health (relationships with family and friends, and perceived stigma resulting from the diagnosis of epilepsy). Individual patient definition of QOL is crucial to achieving the medical goal of seizure control and appropriate antiepileptic drug selection.

Imam et al. ${ }^{32}$ studied 32 adults with epilepsy in Northern Nigeria, using the 10-item version of the quality of life in epilepsy questionnaire (QOLIE-10), and found that the commonest aspect of QOL affected in participants was impaired energy in $46.8 \%$ followed by memory problems in $34.4 \%$. Fear of experiencing another seizure, work and social limitations occurred in 25.8\%, 16.7\% and 10.3\% respectively. Mosaku et al. ${ }^{31}$ also used the same QOLIE-10 on 51 respondents with epilepsy and not only found a lower quality of life amongst the population but also found that depressive symptoms were the single most important factor explaining low QOL with other factors being general psychopathology, seizure frequency, use of more than one antiepileptic drug and female gender

Among adolescents with epilepsy, Adewuya \& Oseni ${ }^{33}$ using a mother rated quality of life in epilepsy questionnaire reported that the predictors of poor quality of life in adolescents with epilepsy included anxiety disorders, depressive disorders, frequency of seizures, and side effects of antiepileptic drugs. In another study of Adewuya $^{34}$, in which the effect of parental psychopathology on the self rated QOL of adolescents with epilepsy was examined - the duration of illness, numbers of antiepileptic drugs and medication toxicity were significantly associated with poor QOL. The study also revealed that self rated depressive symptoms and general psychopathology in the parents were significantly associated with poorer self rated QOL in adolescents with epilepsy

\section{Social issues in epilepsy}

Nigerian patients with epilepsy suffer social deprivation and discrimination in education, employment, housing, 
marital life amongst other components of daily living. ${ }^{35}$ Epilepsy is seen as a highly contagious and shameful disease in the eyes of the public in the country. ${ }^{36}$ This socio-cultural attitude continues to have a negative impact on the management of epilepsy and contributes to poor prognosis and development of complications. ${ }^{37}$ The general attitude toward patients with epilepsy is negative. ${ }^{35,38,39}$ Awaritefe et al. ${ }^{35}$ assessed the attitude of the normal literate general public towards persons with epilepsy versus the "cured" psychotic patient. They found that the general attitude towards the epileptic patient is negative whereas toward the "cured" psychotic patient it is positive. There were gender differences, in that males perceived epileptic patients more favourably than females did. However both male and female participants discriminated against both the epileptic and "cured" psychotic person in terms of employment, residential accommodation, friendship and marital relationship

In a more recent study of 406 randomly selected teachers in primary, secondary and tertiary institutions in the North Central part of Nigeria, about 30.5\% believed that epilepsy could be contracted through the saliva of an epileptic patient, $27.7 \%$ thought it was synonymous with possession with evil spirit while 10\% misunderstood epilepsy for insanity. ${ }^{38}$ The authors noted that a negative attitude and bias against epilepsy were still ingrained among teachers in Nigeria and concluded that the majority of people know little about the aetiology of epilepsy; they had myths, misconceptions and prejudice against epilepsy. A similar study in South Eastern Nigeria reported similar findings. ${ }^{39}$

Amongst the patients with epilepsy themselves, earlier studies by Danesiamong adolescent and adult patients with epilepsy revealed that they felt feared by the lay public who avoided contact with them. ${ }^{40}$ Most epileptic patients however had positive views regarding epilepsy and favourable attitudes toward other epileptic patients. While many believed that epileptic patients were not disabled and had the same intelligence, ambition, and ability to be educated as non epileptic persons, some of them still rated epileptic persons lower than non epileptic persons with respect to contribution to society, hard work, temperament, and ability to make close friends.

Stigma associated with epilepsy in some instances appears to be of greater hindrance than the side effect of the antiepileptic medication. Also the opportunity for marriage and employment are substantially worse for people living with epilepsy and its impact on daily living has been shown to be destructive. ${ }^{38,41}$

\section{Treatment issues}

A large proportion of the 50 million people affected by epilepsy remain untreated. ${ }^{42}$ This "treatment gap" was defined by a workshop of the international league against epilepsy (ILAE) as the difference between the number of people with active epilepsy (two or more unprovoked seizures on different days in the previous year) and the number with controlled seizures in a given population at a given point in time, expressed as a percentage. ${ }^{43}$ While four-fifths of the potential market for antiepileptic drugs is in developing countries, up to $90 \%$ of people with epilepsy in the developing world receive no treatment at all. ${ }^{44,45}$ The reasons for this treatment gap may include failure to identify people with epilepsy; knowledge, attitude and practices (cultural) of the people, as well as the cost of antiepileptic drugs. Misconceptions about epilepsy form the greatest barrier to treatment of persons with epilepsy. ${ }^{36}$

In Nigeria most diseases affecting the brain which include epilepsy are assumed to be due to affliction by evil spirits. ${ }^{37}$ This belief is responsible to a large extent for patients with seizure disorders seeking treatment from traditional healers. Danesi and Adetunji in a survey of 265 epileptic patients in Lagos reported that $47.6 \%$ used African traditional medicine alone, 24.1\% combined traditional medicine with spiritual healing, $20.4 \%$ used spiritual healing alone and $7.5 \%$ used other forms of alternative medicine prior to seeking hospital treatment for epilepsy. ${ }^{46}$ After initiation of hospital treatment, only 14.6\% of patients who had earlier used African traditional medicine continued with such treatment; more than two thirds of the patients who had earlier used spiritual healing continued using such treatment, suggesting that many of these patients perceived some continuing benefits from these alternative treatments. They noted that this observation suggests that alternative medicine, especially spiritual healing, cannot be considered irrelevant in the management of epilepsy in Africa. Recently, in the northern part of Nigeria, Kabir et al reported 47\% for spiritual healing, which was preferred method of treatment for epilepsy, next was allopathic medicine (34\%) while traditional medicine was 19\%. ${ }^{37}$

Ideally, the choice of antiepileptic drug for each patient should be based on seizure type and / or syndrome as well as the individual person's needs. Unfortunately, in most developing countries both the choice and supply of drugs are limited. While older and cheaper drugs, such as phenobarbitone have declined in market share in industrialised nations, their market share in developing countries is higher and increasing more than that of newer antiepileptic drugs. In children, Skyes found that treatment was equally effective for most anticonvulsants when commenced 5 years or more after the onset of seizures and that the anti-convulsant used for most children was phenobarbitone. ${ }^{47}$

Ojuawo \& Joiner had earlier found that therapy with a single appropriate anticonvulsant was usually effective for seizure control in childhood epilepsies except in some patients with focal seizures, infantile spasms, severely delayed developmental milestones and prolonged seizures. ${ }^{21}$ Poor drug compliance remains the major constraint to adequate seizure control, further compounded in this environment by non-availability of drugs and unaffordable costs.

Ogunniyi and Osuntokun evaluated the effectiveness of anticonvulsant drugs in 175 Nigerian epileptic patients and found no significant difference between phenobarbital and phenytoin effectiveness in seizure control. ${ }^{48}$ They concluded that the currently administered anticonvulsants are effective in $67 \%$ of Nigerian patients studied and phenobarbital should remain a major drug because of economic consideration, availability and low side effects profile. Concerning psychological interventions in relation 
to epilepsy, Olley et al. evaluated psychological treatment in epilepsy and concluded that psycho-education was effective in reducing emotional distress in this group. ${ }^{49}$

Although the side effects of the common anticonvulsants had not been effectively studied in Nigeria, Apantaku et al.50 had earlier reported on 52 patients with epilepsy on a long term drug treatment and postulated that the osteomalacic effect of anticonvulsant drugs reported among caucasians does not appear to occur in African patients in a tropical environment- most probably due to the abundance of vitamin D derived from the sun's ultra-violet light.

\section{Cognition and school performance}

Though the rate of intellectual impairment is not accurately known worldwide, a study in Enugu, Nigeria, reported a rate of $18 \%$ among paediatric epileptic patients -studied between 1985 and 1987 - which was more than that of the age-matched general population. ${ }^{19}$ Epilepsy has been found to negatively affect school attendance and academic performance in Nigeria. ${ }^{51,52}$ The adolescents with epilepsy are highly stigmatized and discriminated against in schools by fellow students ${ }^{53}$ and the teachers., ${ }^{37,54}$ Makanjuola ${ }^{55}$ reported that over $36 \%$ of children and $6 \%$ of adolescents with epilepsy in Nigeria had never attended school while Danesi et $\mathrm{al}^{56}$ reported that about half of adolescents with epilepsy who had attended school in Nigeria withdrew from school prematurely because of their seizures. A third of those who were attending normal schools believed that seizures affected their school performance. Adewuya et al compared the school grades of adolescents with epilepsy aged 12 to 18 years $(n=73)$ over the past academic year with the grades of their classmates of the same age and gender. They found that the mean school grades of adolescents with epilepsy are significantly lower than are those of their healthy controls in all the subjects. ${ }^{52}$ The variables that significantly predict poor school performance in adolescents with epilepsy include psychopathology in the caretaker, adolescents' perceived poor family functioning, adolescents' attitude toward the illness, adolescents' felt stigma, externalizing symptoms in the adolescents and duration of illness.

In the study by Ogunrin et al, the pattern of cognitive disturbance in 60 Nigerian with newly diagnosed epilepsy prior to onset of drug therapy was assessed with Fepsy computerized neuropsychological test battery. It was found that patients with epilepsy performed worse than the controls across the spectrum of cognitive tasks assessed with impairment in short-term memory, psychomotor speed and sustained attention. ${ }^{57}$

Imam and Ogunniyi, using the nMini Mental State Examination (MMSE) to assess cognitive impairment, found that there were significantly more epileptics than controls with cognitive dysfunction. The tests of attention, three-item recall and reading were particularly impaired in patients with epilepsy. ${ }^{58}$

Recently Sunmonu et al assessed 82 subjects (41 patients with epilepsy and 41 normal controls) with the modified Community Screening Interview for Dementia (CSID) questionnaire. Patients with epilepsy performed poorly when compared with controls in the domains of language, memory, attention, calculation and praxis, whereas there was no statistically significant difference between the patients and control in orientation scores. Duration of epilepsy and of antiepileptic drug therapy had a significant negative impact on all domains of the CSID whereas type of antiepileptic drug used did not. ${ }^{5}$ Therefore, there is need for heightened awareness of cognitive impairments in epilepsy among healthcare workers to enable selection of cases for further cognitive testing

\section{Conclusion}

Epilepsy, one of the most important non communicable neurological illnesses, is a stigmatizing disorder. It can have a significant impact on the day to day functioning of those with the condition. The social attitudes towards epilepsy may cause more distress to patients and their relatives than the disease itself, in Nigeria. The local cultural contexts (such as cultural beliefs that epilepsy is infectious, transmissible through saliva and attitudes toward them) also add a social and economic burden to the physical burden of the illness. A better understanding of the disorder among the public would allay fears and misconceptions about epilepsy in the community as well as reduce stigmatization towards them. Therefore education of health workers, patients and the wider community on the facts and consequences of epilepsy is essential. Training of healthcare workers in psychological methods of managing epilepsy such as counseling and supportive psychotherapy will help to improve the quality of life of epileptic patients.

\section{References}

1. Arnston P, Droge D, Norton R, Murray E. The perceived psychosocial consequences of having epilepsy. In: Whitman S, Hermann B, eds. Psychopathology in epilepsy: social dimensions. Oxford: Oxford University Press, 1986; 143-61.

2. Jacoby A, Baker GA, Steen N, Potts P, Chadwick DW. The clinical course of epilepsy and its psychological correlates: findings from a UK community study. Epilepsia 1996;37:148-61.

3. Baker G.A. The psychosocial burden of epilepsy. Epilepsia 2002; 43 (6): $26-30$

4. Sunmonu TA, Komolafe MA, Ogunrin AO, Oladimeji BY, Ogunniyi A Intellectual impairment in patients with epilepsy in Ile-Ife, Nigeria. Acta Neurol Scand 2008; 1 18(6):395-401

5. Sunmonu TA, Komolafe MA, Ogunrin AO, Ogunniyi A. Cognitive assessment in patients with epilepsy using the Community Screening Interview for Dementia. Epilepsy Behav 2009; 14(3):5359.

6. Osuntokun BO. Pattern of neurologic illness in tropical Africa.J Neurol Sci. 1971;12:417-42.

7. Senanayake N, Roman GC . Epidemiology of epilepsy in developing countries. Bulletin of World Health Organization 1993;71:247-58.

8. The Global Campaign Against Epilepsy. Geneva, World Health Organization, 2000 (Information Pack for the launch of the Global Campaign's Second Phase, 12-13 February 2001).

9. Osuntokun BO . Epilepsy in Africa: a review. Trop Geogr Med 1978; 31: $24-31$

10. Osuntokun BO, Schoenberg BS, Nottidge VA, Adeuja A, Kale O, Adeyefa A, et al. Research protocol for measuring the prevalence of neurologic disorders in developing countries: results of a pilot study in Nigeria. Neuroepidemiology 1982;1:143-53.

11. Osuntokun BO, Adeuja AOG, Nottidge VA, Bademosi O, Olumide A, Ige $O$, et al. Prevalence of the epilepsies in Nigerian Africans: A 
community-based study. Epilepsia 1987, 28(3): 272-79

12. Dada TO. Epilepsy in Lagos, Nigeria. Afr. J. Med. Sci1 970;1 :16 I -84.

13. Longe AC, Osuntokun BO. Prevalence of neurological disorders in Udo, a rural community in southern Nigeria. Trop. Geogr. Med 1989;41:36-40.

14. Preux PM, Druet-Cabanac M. Epidemiology of epilepsy in subSaharan Africa. Lancet Neurol 2005;4:21-31.

15. Dada TO, Osuntokun BO, Odeku EL . Epidemiological aspects of epilepsy in Nigeria; a study of 639 patients.Dis. Nerv. Syst 1969; 30(12):807-13.

16. Osuntokun BO, Odeku EL . Epilepsy in Ibadan, Nigeria. A study of 522 cases. Afr J Med Sci 1970;1 (2):185-200.

17. Izuora GI, Azubuike JC . Prevalence of seizure disorders in Nigerian children around Enugu. East Afr Med J 1977; 54(5):276-80.

18. Danesi MA, Oni $K$. Profile of epilepsy in Lagos, Nigeria .Trop Geogr Med 1983;35(1):9-13.

19. Ahmed MH, Obembe A. Electroencephalographic abnormalities in 351 Nigerians with epilepsy. West Afr J Med 1991; 10: 21 6-21.

20. Iloeje SO. The pattern of childhood epilepsy with mental retardation in Nigeria. J. Trop. Pediatr 1989; 35(4):163-8.

21. Ojuawo A, Joiner KT. Childhood epilepsy in Ilorin, Nigeria. East Afr Med J1 997;74(2):72-5.

22. Ogunniyi A, Oluwole OSA, Osuntokun BO. Two-year remission in Nigerian epileptics. East Afr Med J 1998; 75: 392-95.

23. Ogunlesi TA, Ogundeyi MM, Olowu AO. Childhood epilepsies in Sagamu, Nigeria. Indian Journal of Peaditrics 2009;76(4):385-389.

24. Danesi MA. Classification of the epilepsies: an investigation of 945 patients in a developing country. Epilepsia 1985; 26: 131-36.

25. Gureje $O$. Interictal psychopathology in epilepsy: prevalence and pattern in a Nigerian clinic. Br J Psychiatry 1991; 158: 700-5

26. Adewuya AO, Ola BA. Prevalence of and risk factors for anxiety and depressive disorders in Nigerian adolescents with epilepsy. Epilepsy Behav 2005; 6: 342-347.

27. Fatoye F, Mosaku K S, Komolafe M, Adewuya A O . Interictal anxiety and depression symptoms in Nigerians with epilepsy: a controlled study. Epilepsy Behav 2006; 9(2): 312-6.

28. Okubadejo NU, Danesi MA, Aina OF, Ojini FI, Adeyemi JD, Olorunshola DA. Prospective case-control study of interictal depression and suicidal ideation in Nigerians with epilepsy. Niger Postgrad. Med. J. 2007; 14(3):204-8.

29. Olley BO. Psychosocial and seizure factors related to depression and neurotic disorders among patients with chronic epilepsy in Nigeria. Afr, J. Med. Sci 2004; 34(1):39-44.

30. Adewuya AO, Ola BA, Okeniyi JAO . Psychiatric morbidity in Nigerian adolescent with epilepsy. J Peadiatr. Neurol2005; 3(3): 153-8.

31. Mosaku KS, Fatoye FO, Komolafe M, Lawal M, Ola BA. Quality of life and associated factors among adults with epilepsy in Nigeria. Int. J. Psychiatry Med 2006; 36(4): 469-81.

32. Imam I, Talabi $O A$, Sanya $E O$, Ogunniyi A. . The quality of life of chronic epileptic patients in Ibadan, Nigeria.Afr.J.Med Med.Sci 2003; 32: $367-369$

33. Adewuya AO, Oseni SBA. Impact of psychiatric morbidity on parent rated quality of life in Nigerian adolescents with epilepsy. Epilepsy Behav. 2005; 7: 497-501

34. Adewuya AO . Parental psychopathology and self-rated quality of life in adolescents with epilepsy in Nigeria. Dev. Med. Child Neurol 2006: 48: 600-603

35. Awaritefe A, Longe AC, Awaritefe M. Epilepsy and psychosis: a comparison of societal attitudes. Epilepsia 1985; 26(1): 1-9.

36. Awaritefe A. Epilepsy: the myth of a contagious disease. Cult Med
Psychiatry 1989; 13(4):449-56.

37. Kabir M, Iliyasu Z, Abubakar IS, Kabir ZS, Farinyaro AU . Knowledge, attitude and beliefs about epilepsy among adults in a northern Nigerian urban community. Ann. Afr. Med 2005; 4(3): 107-112.

38. Sanya EO, Salami TA, Goodman OO, Buhari OI, Araoye MO Perception and attitude to epilepsy among teachers in primary, secondary and tertiary educational institutions in middle belt Nigeria. Trop Doct 2005; 35(3): 153-6.

39. Alikor EA, Essien AA. Childhood epilepsy: knowledge and attitude of primary school teachers in Port Harcourt, Nigeria. Niger J Med 2005; 14(3):299-303.

40. Danesi MA. Patient perspectives on epilepsy in a developing country. Epilepsia 1984; 25(2):184-90.

41. Adamolekun B, Mielke JK, Ball DE. An evaluation of the impact of health worker and patients education on the care and compliance of patients with epilepsy in Zimbabwe. Epilepsia 1999; 40: 507-11.

42. Scott RA, Lhatto SD, Sander JWAS. The treatment of epilepsy in developing countries: where do we go from here? Bul. WHO 2001; 79: 344-351.

43. Meinardi H, Scott RA, Reis R, Sander JW. The treatment gap in epilepsy: the current situation and ways forward. Epilepsia 2001; 42: 136-149.

44. Kale R. Bringing epilepsy out of the shadows. BMJ 1997; 315: 2-3.

45. Shorvon SD, Farmer PJ . Epilepsy in developing countries: a review of epidemiological, sociocultural and treatment aspects. Epilepsia 1988; 29(1): S36-S45.

46. Danesi MA, Adetunji JB. Use of alternative medicine by patients with epilepsy: a survey of 265 epileptic patients in a developing country. Epilepsia 1994; 35(2):344-51.

47. Sykes RM. Epilepsy in children in Benin City, Nigeria. Ann. Trop. Paediat 2002; 22: 287-296.

48. Ogunniyi A, Osuntokun BO. Effectiveness of anticonvulsant therapy in the epilepsies in Nigerian Africans.East Afr Med J 1991; 68(9): 707-13.

49. Olley BO, Osinowo HO, Brieger WR. Psycho-educational therapy among Nigerian adult patients with epilepsy: a controlled outcome study. Patient educ. Couns 2001;42(1): 25-33.

50. Apantaku JB, Afonja OA, Boyo AE. The effect of long term anticonvulsant therapy on serum calcium, phosphate and alkaline phosphate in Nigerian epileptic patients. Trop. Geogr. Med. 1975, 27(4):418-21.

51. Ibekwe RC, Ojinnaka NC, Iloeje SO. Factors influencing the academic performance of school children with epilepsy. J. Trop. Pediatr 2007; 53(5):338-43.

52. Adewuya AO, Oseni SBA, Okeniyi JAO. School performance of Nigerian adolescents with epilepsy. Epilepsia 2006; 47(2): 415-420

53. Matuja WB, Rwiza HT. Knowledge, attitude and practice (KAP) towards epilepsy in secondary school students in Tanzania. Cent. Afr J. Med 1994; 40(1):13-18

54. Ojinnaka NC. Teachers' perception of epilepsy in Nigeria: a community-based study. Seizure 2002; 11:386-391.

55. Makanjuola RO. Psychiatric and social complications of epilepsy in Nigerians. Trop. Geogr. Med 1983;35: 299-304.

56. Danesi MA, Odusote KA, Roberts OO, Adu EO. Social problems of adolescent and adult epileptics in a developing country, as seen in Lagos, Nigeria. Epilepsia 1981; 22(6):689-96.

57. Ogunrin O, Adamolekun B, Ogunniyi AO, Aldenkamp AP. Cognitive function in Nigerians with newly diagnosed epilepsy. Can J Neurol Sci 2000;27(2):148-51.

58. Imam I, Ogunniyi $A$. The value of the mini mental state examination in Nigerian epileptics. Trop Doct 2005; 35(2):108-9. 